\title{
Молекулярно-филогенетическое изучение рода Catabrosa (Poaceae): сравнительный анализ последовательностей ITS1-5.8S рДНК-ITS2 генов 35S рРНК
}

\section{Molecular phylogenetic study of the genus Catabrosa (Poaceae): a comparative analysis of the sequences ITS1-5.8S rDNA-ITS2 in the 35S rRNA genes}

\author{
Матейкович П. А., Пунина Е. О., Носов Н. Н., Мачс Э. М., Родионов А. В. \\ Mateykovich P. A., Punina E. O., Nosov N. N., Machs E. M., Rodionov A. V. \\ Ботанический институт им. В. Л. Комарова РАН, г. Санкт-Петербург, Россия. E-mails: sandhani@yandex.ru, \\ elizaveta_punina@mail.ru,nnosov2004@mail.ru,edw.mach@gmail.com,avrodionov@mail.ru \\ Komarov Botanical Institute of the Russian Academy of Sciences, Saint-Petersburg, Russia
}

\begin{abstract}
Peфepam. Проведен сравнительный анализ последовательностей ITS1-5.8S рДНК-ITS2 генов 35S pPHК у 20 видов и морфотипов рода Catabrosa (поручейница), который до недавнего времени считался монотипным. Выявлено 7 основных гаплотипов, соответствующих отдельным видам, группам видов и некоторым морфотипам. Выдвинуты гипотезы о субгеномной композиции полиплоидных видов C. kneuckeri, C. minor, C. capusii, C. bogutensis и $C$. ledebourii.
\end{abstract}

Ключевые слова. Поручейница, гаплотипы, внутригеномный полиморфизм, Роеае.

Summary. A comparative analysis of the ITS1-5.8S rDNA-ITS2 sequences of the 35S rRNA genes in 20 species and morphotypes of the genus Catabrosa, which until recently was considered monotypic, was performed. Seven major haplotypes were identified, corresponding to individual species, groups of species, and some morphotypes. Hypotheses about the subgenomic composition of polyploid species C. kneuckeri, C. minor, C. capusii, C. bogutensis and C. ledebourii are proposed.

Key words. Haplotype, intragenomic polymorphism, Poeae, water whorlgrass,

Род Catabrosa P. Beauv. (поручейница) долгое время считался монотипным, представленным единственным, описанным из Европы видом C. aquatica (L.) P. Beauv. Некоторые авторы признавали видовую самостоятельность среднеазиатской C. capusii Franch. (Невский, 1934; Bor, 1970). Н. Н. Цвелев (1976) рассматривал C. capusii в ранге подвида C. aquatica, а также в ранге подвида указывал C. aquatica subsp. pseudoairoides (Herrm.) Tzvel., описанную из дельты Волги. Зарубежными исследователями в род Catabrosa были перенесены только два обособленных вида из Южного полушария C. werdermannii (Pilg.) Nicora et Rúgolo (ранее Phippsia werdermannii Pilg.) и C. drakensbergensis (Hedberg et I. Hedberg) Soreng et Fish (ранеe Colpodium drakensbergense Hedberg et I. Hedberg) (Nicora, Agrasar, 1981; Soreng, Fish, 2011). Для Сибири всеми без исключения авторами до настоящего момента была приведена только C. aquatica, без подвидов или разновидностей (Griseb. in Ldb, Fl. Ross. IV, 387; Невский, 1934, во Фл. СССР, 2: 446; Крылов, 1914, во Фл. Алтая и Томск. губ, V-VII: 1637; он же, 1928, во Фл. Зап. Сибири, ІІ: 270; Ломоносова, 1984, в Опр. раст. Тувинской АССР: 309; Никифорова, 1990, во Фл. Сибири, 2: 189; Власова, 2005, в Консп. Фл. Сибири: 294; Красноборов и др., 2012, в Опр. раст. респ. Алтай: 582).

В 2013 г. Н. Н. Цвелев опубликовал новую обработку рода Catabrosa (Цвелев, 2013), где обосновал наличие в роде 12 видов, хорошо отличимых по ареалу, морфологическим признакам и хромосомным числам, и отметил, что при более детальном изучении рода на всем ареале могут быть выявлены и другие виды. Два новых вида в Сибири - C. ledebourii Punina et Nosov и C. bogutensis Punina et Nosov - недавно были выявлены и описаны нами (Punina et. al., 2016). Виды поручейниц образуют по- 
липлоидный ряд; ранее были известны диплоиды - горный кавказский вид C. atrata (Tzvelev) Tzvelev и прикаспийский $C$. pseudairoides (оба $2 n=10$ ); тетраплоиды - европейская $C$. aquatica, гипоарктическая C. minor (Bab.) Tzvelev, среднеазиатская C. capusii (все $2 n=20)$ и гексаплоид $C$. longissima Tzvelev $(2 n=30)$. Описанные же нами C. ledebourii и C. bogutensis оказались октоплоидами с $2 n=40$ (Punina et al., 2016). У части видов, приводимых Н. Н. Цвелевым (2013), кариотипы не изучены и хромосомные числа неизвестны. Такое разнообразие кариотипов с большой вероятностью свидетельствует о том, что эволюция поручейниц сопровождалась неоднократными актами межвидовой гибридизации и последующей полиплоидизации, хотя нельзя исключить и наличие хромосомных рас внутри одного вида (Шнеер и др., 2018).

При определении круга родства и положения рода Catabrosa в системе злаков современные молекулярно-филогенетические исследования однозначно относят этот род к подтрибе Coleanthinae (paнее Puccinelliinae), причем к отдельной монофилетичной кладе в составе подтрибы (Soreng et al., 2015, 2017). Для южноамериканского вида $C$. werdermannii выявлен случай межродовой гибридизации - его ITS-последовательности сходны с таковыми у других видов Catabrosa, а по хлоропластным генам trnLtrnF он группируется с родом Phippsia (Gillespie et al., 2008). В более ранних обработках (Цвелев, 1976) род Catabrosa сравнивался с арктическим родом Dupontia R. Br., но молекулярно-филогенетические исследования подтвердили лишь отдаленное родство поручейницы с указанным родом (Brysting et al., 2004; Gillespie et al., 2008). Молекулярно-филогенетическое исследование видов внутри рода Catabrosa только начинается. Начальный этап работ по секвенированию ITS-последовательностей нескольких российских видов выполнен нами (Nosov et. al., 2017); было показано, что, во-первых, род Catabrosa является монофилетичным, а во-вторых, по этим последовательностям ряд видов хорошо различается между собой.

В дальнейшем, при просмотре некоторых гербарных коллекций мы предположили, что видовое разнообразие рода заметно больше. Мы выявили различные морфотипы среди сборов из центральной части России, Кавказа, Восточной Сибири, Казахстана, Ирландии и Северной Америки (гербарии LE, MHA, MW). Некоторые необычные морфотипы недавно были собраны нами в природе (Московская обл. и Республика Дагестан). Они отличаются по таким признакам, как размер и форма метелки, количество цветков в колоске, наличие опушения на нижних цветковых чешуях, окраска, размеры и соотношение колосковых чешуй, и по совокупности признаков не подходят под описание уже известных видов. Возможно, что часть этих морфотипов заслуживает в будущем описания в ранге самостоятельных видов. Некоторые образцы, возможно, имеют гибридное происхождение. Так, в гербариях LE и MНА нами были найдены образцы, морфологически промежуточные между C. aquatica и C. kneuckeri Tzvelev (Северо-Западный регион) или между C. aquatica и описанным нами видом C. ledebourii (Забайкалье), и некоторые другие.

В настоящей работе мы секвенировали по Сэнгеру последовательность ITS1-5.8S рДНК-ITS2 у 35 образцов поручейниц. Часть образцов была собрана авторами в природе, часть - любезно предоставлена нашими коллегами из их личных сборов, часть - взята из гербариев MHA и MW. Также в анализ включены и 7 последовательностей из GenBank.

Секвенирование последовательностей ДНК проводили в ЦКП БИН РАН на генетическом анализаторе AbiPrism 3130 (Applied Biosystems). Полученные хроматограммы визуально проверялись на наличие полиморфных сайтов. Анализ последовательностей ДНК выполняли с помощью программ MEGA 7.0 (Kumar et al., 2016) и Chromas (http://technelysium.com.au/wp/chromas/). Оптимальная эволюционная модель для расчета филогенетических деревьев была получена с использованием алгоритма Likelihood ratio test в программах MEGA 7.0 и jModelTest 2. 1.6 (Darriba et al., 2012). Филогенетически значимые индели в выравнивании были закодированы с помощью программы SeqState 1.4.1 (Müller, 2005) и добавлены в матрицу как бинарные состояния (binary data). Молекулярно-филогенетический анализ проводили с помощью программы Mr. Bayes 3.0 (Huelsenbeck, Ronquist, 2001), эволюционная модель GTR+I+G, 2 млн генераций, первые 25 \% деревьев были исключены как "burn-in".

Полученное филогененическое древо показано на рисунке (рис.). Часть исследованных нами видов и морфотипов формирует хорошо поддерживаемые клады, но значительная их часть занимает неопределенное положение в роде Catabrosa. Так, обособлены от прочих видов все алтайские образцы 
C. ledebourii и C. bogutensis; эти октоплоидные виды хорошо различаются между собой морфологически. Хорошо выделяется группа C. pseudairoides $+C$. kneuckeri $+C$. minor, где C. pseudairoides - диплоид, а два остальных - тетраплоиды. В отдельную кладу попадают и южноамериканские образцы с неизвестным хромосомным числом. Высокогорный среднеазиатский тетраплоидный вид C. capusii оказался сходен с двумя образцами из Испании (GenBank) и секвенированными нами образцами из Ирландии и Дагестана; причем все секвенированные нами образцы имели как морфологические, так и молекулярные различия в пределах клады. Неожиданным оказалось сходство образца из Калмыкии, который мы изначально определили как $C$. aquatica, и образца из Вологодской обл., определенного нами как гибрид C. kneuckeri $\times$ C. aquatica. Прочие образцы, часть из которых мы определили как C. aquatica, а часть как новые морфотипы, заняли неопределенное положение.

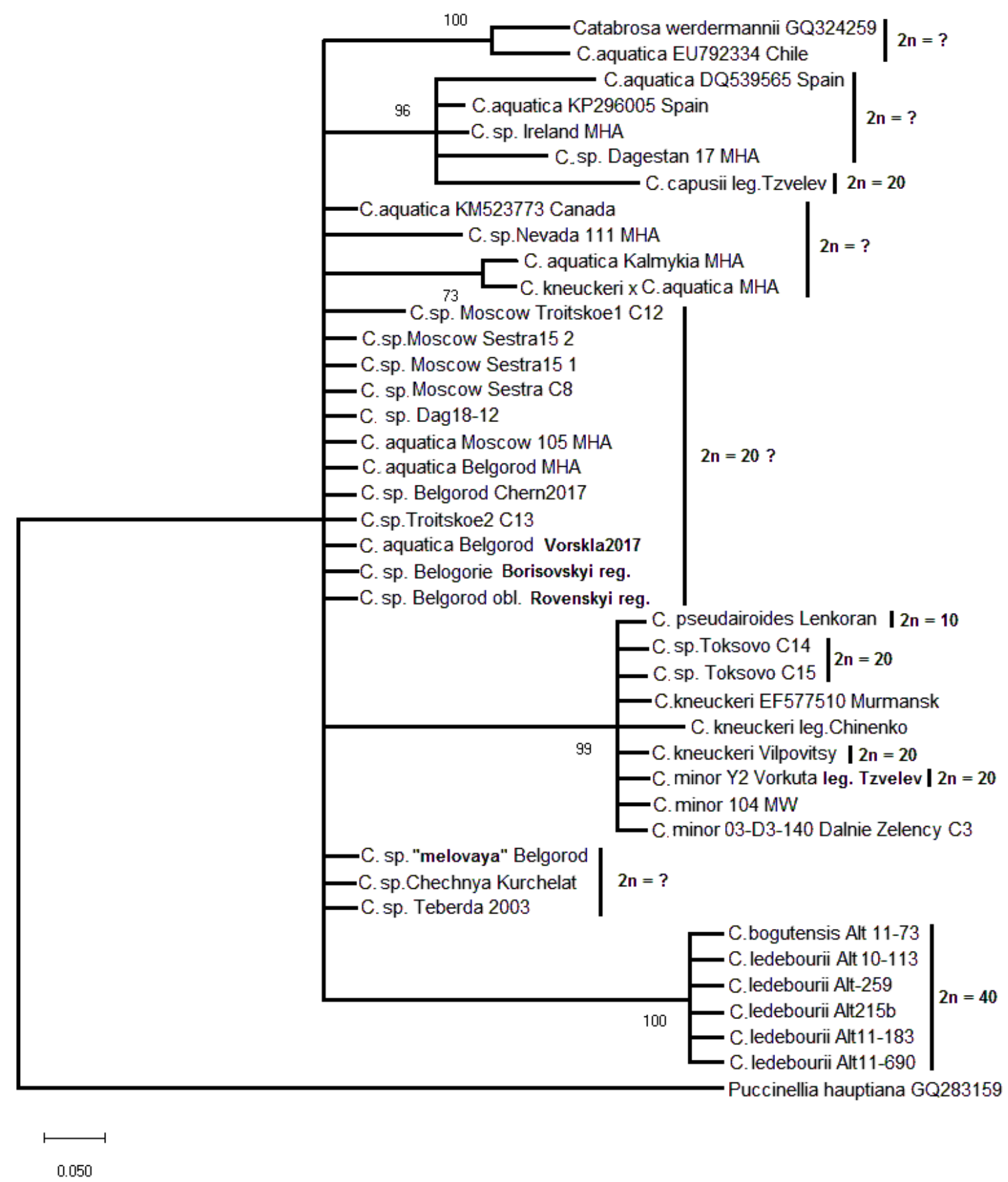

Рис. Филогенетическое древо рода Catabrosa, построенное методом Байеса по результатам секвенирования последовательностей ITS1-5.8S рДНК-ITS2. 
Таблица

Соответствие видов/морфотипов и гаплотипов у исследованных образцов поручейниц. VN - однонуклеотидные замены и индели, PS - полиморфные сайты

\begin{tabular}{|c|c|c|c|c|}
\hline Образец & Морфотип & Гаплотип & $\begin{array}{c}\mathrm{VN} \text { в } \\
\text { пределах } \\
\text { гаплотипа } \\
\end{array}$ & PS \\
\hline $\begin{array}{l}\text { C. werdermannii GQ324259 } \\
\text { C. aquatica EU792334 Chile }\end{array}$ & $?$ & werdermannii & 2 & 1 \\
\hline $\begin{array}{l}\text { C. aquatica DQ539565 Spain } \\
\text { C. aquatica KP296005 Spain }\end{array}$ & $?$ & capusii 2 & 3 & 0 \\
\hline C. $s p$. Ireland (MHA) & «Ирландия» & capusii 3 & 6 & 3 \\
\hline C. $s p$. Dagestan 17 (MHA) & «Армения» & capusii 4 & 6 & 0 \\
\hline C. capusii (leg. N.N.Tzvelev) & capusii & capusii 1 & - & 1 \\
\hline C. aquatica Kalmykia (MHA) & «Калмыкия» & Kalmykia & - & $3-4$ \\
\hline C. kneuckeri $\times$ C. aquatica (MHA) & kneuckeri $\mathrm{x}$ aquatica & Kaimyкıа & - & $3-4$ \\
\hline C. $s p$. Nevada 111 (MHA) & «Невада» & Nevada & - & 5 \\
\hline C. aquatica KM523773 Canada & $?$ & aquatica 1 & - & 0 \\
\hline C. $s p$.Troitskoe2_C13 & \multirow{3}{*}{ aquatica } & aquatica 2 & 1 & 10 \\
\hline $\begin{array}{l}\text { C. aquatica } \text { Belgorod Vorskla2017 } \\
\text { C. sp. Teberda } 2003 \\
\text { C. sp. Chechnya Kurchelat C17 }\end{array}$ & & aquatica 3 & $0-1$ & $8-12$ \\
\hline $\begin{array}{l}\text { C. sp. Belgorod Chern } 2017 \text { Oskol } \\
\text { C. aquatica Belgorod (MHA) }\end{array}$ & & aquatica 4 & 1 & $2-4$ \\
\hline C. $s p$. Moscow Troitskoe1_C12 & \multirow{3}{*}{ "Московская" } & aquatica 5 & 1 & 4 \\
\hline $\begin{array}{l}\text { C. } s p . \text { Moscow Sestra15_2 } \\
\text { C. } s p . \text { Moscow Sestra15_1 } \\
\text { C. } s p . \text { Sestra C } 8\end{array}$ & & aquatica 6 & $1-2$ & 5 \\
\hline C. aquatica Moscow 105 (MHA) & & \multirow{4}{*}{ aquatica 7} & \multirow{4}{*}{$0-1$} & \multirow{4}{*}{$9-10$} \\
\hline C. $s p$. Dag18-12 & "Гуниб" & & & \\
\hline $\begin{array}{l}\text { C. } s p \text {. Belgorod Borisovsky reg. } \\
\text { C. } s p \text {. Belgorod obl._Rovenskii reg. }\end{array}$ & aquatica & & & \\
\hline C. sp. melovaja Belgorod & "меловая" & & & \\
\hline C. pseudairoides Lenkoran (leg. Tzvelev) & pseudairoides & \multirow{3}{*}{ pseudairoides 1} & \multirow[b]{3}{*}{-} & \multirow[b]{3}{*}{$0-4$} \\
\hline $\begin{array}{l}\text { C. sp. Toksovo (leg. Konechnaya) C14 } \\
\text { C. sp. Toksovo (leg. Konechnaya) C15 }\end{array}$ & "Токсово" & & & \\
\hline $\begin{array}{l}\text { C. kneuckeri EF577510 Murmansk (leg.Chinenko) } \\
\text { C. kneuckeri (leg.Chinenko) } \\
\text { C. kneuckeri Vilpovitsy }\end{array}$ & kneuckeri & & & \\
\hline $\begin{array}{l}\text { C. minor Y2 Vorkuta (leg. Tzvelev) } \\
\text { C. minor } 104 \text { (MW) } \\
\text { C. minor 03-D3-140 Dalnie Zelencu C3 }\end{array}$ & minor & pseudairoides 2 & 0 & 2 \\
\hline C. bogutensis Alt 11-73 & bogutensis & \multirow[b]{2}{*}{ ledebourii } & \multirow[b]{2}{*}{ - } & \multirow[b]{2}{*}{$0-5$} \\
\hline $\begin{array}{l}\text { C. ledebourii Alt 10-113 } \\
\text { C. ledebourii Alt } 259 \\
\text { C. ledebourii Alt } 215 \mathrm{~b} \\
\text { C. ledebourii Alt } 11-183 \\
\text { C. ledebourii Alt 11-690 }\end{array}$ & ledebourii & & & \\
\hline
\end{tabular}


Всего в последовательности ITS1-5.8S рДНК-ITS2 у представителей рода Catabrosa мы выявили 49 вариабельных позиций, которые можно считать парсимонично информативными (однонуклеотидные замены и индели (VN), полиморфные сайты (PS)); из них 24 - в спейсере ITS1, 5 - в гене 5.8S рДНК и 20 - в спейсере ITS2.

На основании визуального анализа этих вариабельных позиций мы попытались выявить основные и дополнительные гаплотипы у представителей рода Catabrosa и сопоставить их с видовой принадлежностью и/или морфотипами исследованных образцов. Результаты показаны в таблице (табл.). Мы выделили 7 основных гаплотипов, условно назвав их «werdermannii», «capusii», «aquatica», «pseudairoides», «ledebourii», «Kalmykia», «Nevada». Внутри гаплотипов «сарusii», «aquatica» и «pseudairoides» можно выделить дополнительные гаплотипы, различающиеся небольшим количеством $\mathrm{VN}$, а внутри гаплотипа «aquatica» - и значительным количеством PS, которые свидетельствуют о внутригеномном полиморфизме последовательностей ITS1-5.8S рДНК-ITS2 у исследованных образцов. Этот внутригеномный полиморфизм может быть как следствием гибридной природы образца (Рunina et al., 2012, 2017; Rodionov et al., 2018, Родионов и др., 2019), так и свидетельством активной внутривидовой дивергенции (Ефимов и др., 2017). На таблице видно, что в некоторых случаях гаплотипы соответствуют одному или нескольким видам или морфотипам, а в некоторых такого соответствия нет или же оно неочевидно.

Только в одном случае нам удалось показать, что гаплотип «pseudairoides» соответствует субгеному у диплоидного вида C. pseudairoides. Такой же гаплотип был выявлен у тетраплоидных C. kneuckeri и C. minor, и можно сделать вывод о том, что геномы этих видов содержат субгеном C. pseudairoides. По-видимому, общий субгеном есть у тетраплоидной $C$. сариsii и нескольких образцов с неизвестным хромосомным числом из различных географических локаций. В геномной композиции октоплоидных сибирских C. bogutensis и C. ledebourii - один уникальный и три пока еще неизвестных субгенома.

Вопрос о видовой самостоятельности выделенных нами новых морфотипов, так же как и вопрос о субгеномном составе и эволюционной истории поручейниц пока остается открытым. Для их решения необходимо привлечение более широкого круга объектов, определение их хромосомных чисел, секвенирование хлоропластных последовательностей ДНК и NGS-секвенирование.

Работа выполнена на оборудовании ЦКП «Клеточные и молекулярные технологии изучения растений и грибов» при поддержке гранта РФФИ № 18-04-01040 и частично Программы Президиума РАН «Биоразнообразие природных систем» (проект № 0126-2018-0029). Авторы благодарят Г. Ю. Конечную, Н. М. Решетникову, С. В. Чиненко, Ю. М. Пунина и О. А. Корнилову за предоставленные гербарные образцы и помощь в сборе материала.

\section{ЛИТЕРАТУРА}

Ефимов С. В., Дегтярева Г. В., Терентьева Е. И. и др. Изучение полиморфизма ампликонов ITS1 и ITS2 ядерной рибосомальной ДНК с помощью высокопроизводительного параллельного секвенирования и прямого секвенирования по Сэнгеру у Paeonia lactiflora (Paeoniaceae) // Проблемы ботаники Южной Сибири и Монголии, 2017. - № 16. - С. 246-249.

Невский С. А. Поручейница - Catabrosa P. Beauv. // Флора СССР. - Л., 1934. - Т. 2. - С. 445-446.

Родионов A. В., Амосова A. В., Беляков $\boldsymbol{E}$. A. и др. Генетические последствия межвидовой гибридизации, ее роль в видообразовании и фенотипическом разнообразии растений // Генетика, 2019. - Т. 55, № 3. - С. 255-272.

Цвелев Н. Н. Злаки СССР. - М.: Наука, 1976. - 788 с.

Цвелев $\boldsymbol{H} . \boldsymbol{H}$. Заметки о некоторых родах семейства злаков (Роасеае) // Новости сист. высш. раст., 2013. - Т. 44. - C. $26-38$

Шнеер В. С., Пунина $\boldsymbol{E}$. O., Родионов $\boldsymbol{A}$. В. Внутривидовые различия в плоидности у покрытосеменных и их таксономическая интепретация // Бот. журн., 2018. - Т. 103. - № 5. - С. 555-585.

Bor N. L. Flora Iranica: Gramineae // in Rechinger, K. H. (ed.), $1970-573$ p.

Brysting A. K., Fay M. F., Leitch I. J., Aiken S. G. One or more species in the arctic grass genus Dupontia? - a contribution to the Panarctic Flora project // Taxon, 2004. - T. 53. - №. 2. - C. 365-365.

Darriba D., Taboada G. L., Doallo R., Posada D. jModelTest 2: more models, new heuristics and parallel computing // Nature methods, 2012. - T. 9. - №. 8. - C. 772. 
Gillespie L. J., Soreng R. J., Bull R. D. et al. Phylogenetic relationships in subtribe Poinae (Poaceae, Poeae) based on nuclear ITS and plastid trn T-trn L-trn F sequences //Botany, 2008. - T. 86. - №. 8. - C. 938-967.

Huelsenbeck J. P., Ronquist F. MRBAYES: Bayesian inference of phylogenetic trees // Bioinformatics, 2001. - V. 17. - I. 8. - P. 754-755.

Kumar S., Stecher G., Tamura K. MEGA7: Molecular Evolutionary Genetics Analysis version 7.0 for bigger datasets // Molecular Biology and Evolution, 2016. - V. 33. - I. 7. - P. 1870-1874. DOI: 10.1093/molbev/msw054.

Müller K. SeqState: primer design and sequence statistics for phylogenetic DNA datasets // Appl Bioinformatics. 2005. - V. 4. - I. 1. - P. 65-69.

Nicora E. G., Agrasar Z. R. Catabrosa P. Beauv. y Phippsia R. Brown (Gramineae) en America del Sur. // Darwiniana, 1981. - Vol. 23, № 1. - P. 179-188.

Nosov N. N., Punina E. O., Machs E. M, Rodionov A. V. Genomic composition of polyploid species in the genus Catabrosa P. Beauv. (Poaceae) as revealed by molecular phylogenetic analysis // Skvortsovia, 2017. - Vol. 4. - № 1. - P. $18-21$.

Punina E. O., Machs E. M., Krapivskaya E. E. Interspecific hybridization in the genus Paeonia (Paeoniaceae): polymorphic sites in transcribed spacers of the $45 \mathrm{~S}$ rRNA genes as indicators of natural and artificial peony hybrids // Russ. J. of Genetics, 2012. - V. 48, № 7. - C. 684-697.

Punina E. O., Machs E. M., Krapivskaya E. E., Rodionov A. V. Polymorphic sites in transcribed spacers of 35s rRNA genes as an indicator of origin of the Paeonia cultivars // Russ. J. of Genetics., 2017. - V. 53, № 2. - C. $202-212$.

Punina E. O., Nosov N. N., Myakoshina Y. A. et al. New octoploid Catabrosa (Poaceae) species from Altai // Kew Bulletin, 2016. - V. 71. - № 3:35. DOI 10.1007/S12225-016-9646-5

Rodionov A. V., Dobryakova K. S., Punina E. O. Polymorphic sites in ITS1-5.8S rDNA-ITS2 region in hybridogenic genus $\times$ Elyhordeum and putative interspecific hybrids Elymus (Poaceae: Triticeae) // Russ. J. of Genetics, 2018. -V. 54, № 9. - C. 1025-1039.

Soreng R. J., Fish L. Catabrosa versus Colpodium (Poaceae: Poeae) in southern Africa, with a key to these genera and their species in Africa // Kew. Bull., 2011. - Vol. 66, № 1. - P. 101 - 110.

Soreng R. J. Peterson P. M., Romaschenko K. et al. A worldwide phylogenetic classification of the Poaceae (Gramineae) //Journal of Systematics and Evolution, 2015. - T. 53. - №. 2. - C. 117-137.

Soreng R. J. Peterson P. M., Romaschenko K. et al. A worldwide phylogenetic classification of the Poaceae (Gramineae) II: An update and a comparison of two 2015 classifications //Journal of Systematics and Evolution, 2017. - T. 55. - №. 4. - C. 259-290. 